\title{
New directions for psychiatric rehabilitation in the USA
}

\author{
G. R. Bond* and R. E. Drake \\ Westat Inc, Health Studies Sector, Rivermill Commercial Center, 85 Mechanic St., Lebanon, New Hampshire 03766, USA
}

\begin{abstract}
American researchers have led the world in developing, evaluating, and disseminating evidence-based psychiatric rehabilitation practices for people with serious mental illness. Paradoxically, however, the USA lags behind most industrialized nations in providing access to high-quality mental health and psychiatric services. This essay examines several evidence-based practices developed in the USA, the spread of these practices, the barriers to ensuring availability to people who could benefit from these services, and some promising directions for overcoming the barriers. Factors influencing the growth and sustainment of effective client-centred practices include the availability of adequate and stable funding, committed leadership, and the influence of vested interests. Two strategies for promoting the spread and sustainment of well-implemented evidence-based practices are the adoption of fidelity scales and learning communities.
\end{abstract}

First published online 21 November 2016

Key words: Community mental health, evidence-based psychiatry, rehabilitation, schizophrenia.

In this essay we describe the status of psychiatric rehabilitation services in the USA and offer our recommendations for future directions. We examine this paradox: while the USA has led the way in developing, researching and disseminating evidence-based psychiatric rehabilitation services around the world (Corrigan et al. 2008), the quality of mental health treatment and rehabilitation services in the USA lags behind services in many other industrialised nations, much as does the overall US health care system. The USA consistently ranks far below most countries in a wide range of health indicators despite its much higher per capita expenditure for health care (Squires \& Anderson, 2015). The US health care system is expensive, inefficient and diverse - essentially a non-system producing enormous disparities in care. Thus far, health care reform through the Affordable Care Act has not led to wider adoption of evidence-based care for Americans with serious mental illness (Olfson et al. 2013).

Mental health services in the USA are funded through a combination of different private insurances (mostly for families covered by employer benefits and others receiving coverage through health exchanges) and public insurance through Medicaid, Medicare, benefits to military veterans and other programs. Only a minority of Americans with serious mental illness receive any mental health treatment at all (Wang et al. 2005). Private health insurance rarely

\footnotetext{
* Address for correspondence: G. R. Bond, Westat Inc, Health Studies Sector, Rivermill Commercial Center, 85 Mechanic St., Lebanon, New Hampshire 03766, USA.

(Email: garybond@westat.com)
}

pays for psychiatric rehabilitation services. Among Americans with serious mental illness who do receive mental health and rehabilitation services most do so as clients in public mental health clinics funded primarily through Medicaid. People with mental health needs are often unhappy with available mental health services; approximately one-third of those who have contact with the mental health service system drop out quickly (Kreyenbuhl et al. 2009). Largely because of systemic problems, $<5 \%$ of people with serious mental illness receive high-quality psychiatric rehabilitation services (Drake et al. 2009).

Despite the wide endorsement of recovery as a guiding principle of psychiatric rehabilitation (Anthony, 1993), state mental health agencies in the USA, through their state Medicaid plans, continue to support outdated psychosocial services, such as brokered case management services, day treatment and institutionbased skills training. To maximise Medicaid reimbursement, mental health providers often offer predominantly group modalities even when clients prefer, and might benefit more, from individualised services. Moreover, state mental health spending includes sizeable allocations of funding for psychotropic medications, out of proportion to any benefits and to a large extent antithetical to recovery (Drake et al. 2008). The US mental health system serves vested interests rather than client interests.

This essay examines several evidence-based practices (EBPs) developed in the USA, the spread of these practices, the barriers to ensuring availability to people who could benefit from these services and some promising directions for overcoming the barriers. 


\section{The evidence base for effective psychiatric rehabilitation practices}

People with severe mental illness have the same life goals as everyone else. These goals include a safe, decent, affordable and permanent place to live, access to education and employment, friendships and community participation in leisure and growth activities. In other words, they want to live satisfying, functional, meaningful lives, not just be stable (Deegan, 1988; Drake \& Whitley, 2014). To be client-centred, psychiatric rehabilitation should aim at realising these life goals. Are these goals attainable?

Experts defined evidence-based medicine as 'the conscientious, explicit, and judicious use of current best evidence in making decisions about the care of individual patients' (Sackett et al. 1996). A 1998 conference of mental health leaders called for systematic attention to its application to psychiatric rehabilitation practices (Drake et al. 2001). Researchers, primarily from the USA, have identified a large and growing number of effective psychiatric rehabilitation practices (Corrigan et al. 2008; Dixon et al. 2010). Evidence-based models have been developed for many recovery goals, including employment (Marshall et al. 2014), independent living (Rog et al. 2014) and community living skills (Bond \& Drake, 2015). Illness self-management approaches, such as the Wellness Recovery Action Planning, foster attainment of personal life goals (Cook et al. 2012). In other life domains, notably the interpersonal realm (social networks, friendship and intimacy), establishing EBPs has been more difficult (Davidson et al. 2004). More research is needed, of course, but the more serious issue is that practices for which the evidence is well established are not widely available. This gap between what practices are effective and which are actually available and delivered with high fidelity - what has been termed the science-to-service gap (Drake \& Essock, 2009) - is the most pressing problem in the US public mental health system.

\section{Lack of evidence-based psychiatric rehabilitation practices}

According to reports from state mental health leaders in their annual reports for the Federal Block Grant, approximately $2 \%$ of clients with serious mental illness enrolled in the public mental health system have access to evidence-based psychiatric rehabilitation services, a statistic that has remained steady in reports over the last decade (Bruns et al. 2016). Service gaps occur at three levels: states that have not adopted practices into their state plans, limited penetration within states that have adopted a practice and limited capacity to serve clients within programs once practices are established.

States began adopting EBPs in the early 2000s. After this initial effort, however, the uptake of EBPs levelled off or declined over the next decade (Bruns et al. 2016). Many states have made only minimal progress.

The national data sets compiled by Bruns et al. (2016) provide the most comprehensive snapshot of the spread of EBPs in the USA. These data, based on self-reported surveys that state leaders completed on an annual basis for federal reporting purposes, are the only systematic information we have for most practices. These annual surveys provide only rough estimates of the spread of EBPs and virtually no information on penetration at the client level.

A 2015 national survey on the prevalence of evidence-based employment services known as Individual Placement and Support (IPS) (JohnsonKwochka et al. submitted) yielded greater detail. Of the 50 states and District of Columbia, 38 (75\%) offered IPS services, reporting a total of 523 IPS programs nationwide. The state IPS program penetration rate (number of IPS programs per 10000 people) ranged from 0.01 to $1.67(M=0.36$, S.D. $=0.37)$ in the 38 states reporting IPS services. IPS programs vary widely in size, but two large IPS surveys suggested an average program caseload size of about 60 (Bond et al. 2012; Kim et al. 2015). Using these figures, we concluded that over 30000 clients with serious mental illness in the USA received IPS services in 2015. Given that the 2010 US Census reported roughly 200 million working-age Americans, and assuming 5\% of the population, or about 10 million people, had a serious mental illness, the percentage of Americans with serious mental illness receiving IPS is approximately $0.3 \%$ - a tiny fraction of the $70 \%$ who want to work and could potentially benefit.

Why do American citizens lack access to EBPs despite abundant national resources? We next examine several key barriers and facilitators to adoption, implementation, sustainment and expansion of evidencebased psychiatric rehabilitation programs, drawing on a framework shown in Table 1. This table is adapted from a framework developed in a national study examining implementation and sustainment of EBPs (Torrey et al. 2012).

\section{What are the barriers?}

Many factors have prevented the spread of evidencebased psychiatric rehabilitation services. Since the 1950s, psychiatric rehabilitation services in the USA have been underfunded, requiring program leaders to access a patchwork of federal, state, local and 
Table 1. Operational definitions for implementation/sustainability factor domains

\begin{tabular}{|c|c|}
\hline Domain & Definition \\
\hline Financial & $\begin{array}{l}\text { Agency finances, agency resources, state or national budgetary policies, reimbursement } \\
\text { mechanisms, or general economic trends promote/inhibit spread of evidence-based practice } \\
\text { (EBP) }\end{array}$ \\
\hline Leadership & $\begin{array}{l}\text { Leader actions promote/inhibit novel and productive solutions to challenges; ensuring practitioner } \\
\text { have necessary resources to provide services; expressing enthusiastic support for EBP }\end{array}$ \\
\hline Prioritisation & $\begin{array}{l}\text { Support for EBP from staff, clinical team, agency leadership, or state/city/county mental health } \\
\text { agencies promote/inhibit EBP }\end{array}$ \\
\hline Quality improvement & $\begin{array}{l}\text { Systematic monitoring of program fidelity and client outcomes and use of data are/are not } \\
\text { provided via financial incentives and penalties, administrative rules and regulations, ongoing } \\
\text { supervision and feedback on practices }\end{array}$ \\
\hline Workflow & $\begin{array}{l}\text { Work flow is/is not structured so that routine procedures enable EBP (e.g., integration of services, } \\
\text { documentation burden, physical environment, or non-financial policies) }\end{array}$ \\
\hline Workforce & $\begin{array}{l}\text { Appropriately credentialed practitioners and supervisory staff with necessary mastery and } \\
\text { training are/are not available for team to function with fidelity to the model }\end{array}$ \\
\hline $\begin{array}{l}\text { Training and technical } \\
\text { assistance }\end{array}$ & $\begin{array}{l}\text { Training, technical assistance and resource material specific to the EBP are/are not available on an } \\
\text { ongoing basis through a technical assistance centre, which provides training to new employees, } \\
\text { ongoing onsite training, consultation and a regular schedule of workshops to ensure a well- } \\
\text { educated work force }\end{array}$ \\
\hline
\end{tabular}

private funding sources, each with its own set of eligibility requirements, funding caps, time limits and documentation procedures. The lack of adequate and predictable funding is the most significant barrier to adopting and sustaining EBPs (Seffrin et al. 2009; Wiltsey Stirman et al. 2012). State Medicaid plans often make it far easier to finance outmoded services than evidence-based rehabilitation services. Despite its mandate to promote quality of care, the Centers for Medicare and Medicaid Services, which is the federal agency responsible for giving guidance to states on their Medicaid plans, has been timid in providing clear instructions that would empower state leaders to pursue evidence-based rehabilitation services. Medicaid funding typically incentivises group services over individualised services, clinic-based services over communitybased services and medication-related services over non-pharmacological self-management approaches.

State mental health directors experience myriad pressures: legislators demand cost cuts, industry lobbyists want to expand pharmacology, families prioritise protecting vulnerable patients, providers often desire to maintain current services and so on. EBPs may be low on the list. Furthermore, these leaders have such short tenure in their jobs that continuity of system development suffers. The public mental health workforce is typically not prepared to deliver EBPs, and state funds for retraining have been severely diminished.

Pharmaceutical companies have aggressively and successfully marketed many new and costly antidepressant and antipsychotic medications initially hailed as having both greater efficacy and fewer side effects. Studies subsequently have disproved these claims, and companies have paid large settlements to the Department of Justice related to false advertising. The heavy marketing and adoption of these drugs had a further negative effect; funding for community rehabilitation services shrank precipitously as state mental health agencies allocated increasing proportions of their budgets for the new medications (Drake et al. 2008). Compounding this problem is the federal law forbidding the Centers for Medicare and Medicaid Services from negotiating with pharmaceutical companies on the price of medications, in contrast to other nations.

\section{What are the facilitators?}

Notwithstanding slow progress, several developments may give optimism. Payment is of course the chief vehicle for reform. Government and private insurers are currently shifting from paying for the amount of services to paying for valued outcomes. If implemented broadly, these payment changes should decrease ineffective and harmful services and promote those that actually help people.

The federal government and private foundations have helped to promote EBPs by sponsoring demonstrations, such as the National Evidence-based Practices Project (McHugo et al. 2007). Demonstrations are often short-lived when states do not sustain funding and leadership. State leaders can influence the spread of EBPs through establishing standards, 
incentivising effective services, aligning policies and monitoring services (Finnerty et al. 2009). Two strategies that have helped many states are the adoption of fidelity scales and learning communities.

Program fidelity refers to provision of services consistent with objective criteria defined by a program model. Since the late 1990s, researchers, mostly in the USA, have developed, validated and refined a series of EBP fidelity scales (McHugo et al. 2007), including scales for IPS (Bond et al. 2012), assertive community treatment (Monroe-DeVita et al. 2011), Housing First (Gilmer et al. 2013) and Illness Management and Recovery (McGuire et al. 2012). These scales have enabled state authorities to monitor programs and to ensure quality. Many of these scales have been widely adopted, and some states require programs to be certified by achieving high fidelity to receive enhanced rates for provision of evidence-based services (SAMHSA, 2015).

A 'learning community' is defined as a network of organisations with a shared goal of improving treatment for a specific medical condition, facilitated by regular communication (for example, meetings, teleconferences and newsletters) and collection and dissemination of objective information about procedures and outcomes, with a long-term commitment to quality and expansion (Bond et al. 2016). Learning communities build on and systematically integrate the individual implementation strategies identified in Table 1 (prioritising EBPs, fidelity monitoring, training and technical assistance, provision of adequate funding). Learning communities can promote dissemination of information, quality of implementation, sustainment and expansion of evidence-based programs (Bond et al. 2016).

The courts have also helped. A 1999 US Supreme Court case - the Olmstead decision - has promoted expansion of evidence-based psychiatric rehabilitation services (Burnim, 2015). Based on the Americans with Disabilities Act of 1990, the Court ruled that states must provide community services to enable people with disabilities to live in their own homes instead of institutions or congregate facilities. This decision has also been interpreted to encompass full social inclusion. Subsequently, the US Department of Justice has forced numerous states to provide statewide dissemination of a range of evidence-based psychiatric rehabilitation services, including assertive community treatment, supported housing and IPS supported employment (Burnim, 2015).

\section{Conclusions}

In the decade ahead, how can psychiatric rehabilitation leaders transform the US service system to actualise the goal of helping people with serious mental illness lead productive, meaningful and satisfying lives and full integration into the community? The failure to implement our service systems to align with this vision is not for lack of an evidence base. The core principles of psychiatric rehabilitation and associated EBPs have been well described (Corrigan et al. 2008). Change must come from political action. People with psychiatric impairments, their families and their many supporters, unshackled from stigma, will need to demand better services - high quality, evidence-based, person-centred services - rather than ideological tropes. Training institutions, providers and state and local infrastructures will transform when the public demands reach a threshold.

\section{Financial Support}

The authors received no financial support to write this editorial from any funding agency, commercial or notfor-profit sectors.

\section{Conflict of Interest}

None.

\section{References}

Anthony WA (1993). Recovery from mental illness: the guiding vision of the mental health service system in the 1990s. Psychosocial Rehabilitation Journal 16, 11-23.

Bond GR, Drake RE (2015). The critical ingredients of assertive community treatment: an update. World Psychiatry 14, 240-242.

Bond GR, Peterson AE, Becker DR, Drake RE (2012). Validating the revised individual placement and support fidelity scale (IPS-25). Psychiatric Services 63, 758-763.

Bond GR, Drake RE, Becker DR, Noel VA (2016). The IPS learning community: a longitudinal study of sustainment, quality, and outcome. Psychiatric Services 67, 864-869.

Bruns EJ, Kerns SE, Pullmann MD, Hensley SW, Lutterman T, Hoagwood KE (2016). Research, data, and evidencebased treatment use in state behavioral health systems, 2001-2012. Psychiatric Services 67, 496-503.

Burnim I (2015). The promise of the Americans with Disabilities Act for people with mental illness. Journal of the American Medical Association 313, 2223-2224.

Cook JA, Copeland ME, Floyd CB, Jonikas JA, Hamilton MM, Razzano L, Carter TM, Hudson WB, Grey DD, Boyd $S$ (2012). A randomized controlled trial of effects of Wellness Recovery Action Planning on depression, anxiety, and recovery. Psychiatric Services 63, 541-547.

Corrigan PW, Mueser KT, Bond GR, Drake RE, Solomon P (2008). Principles and Practice of Psychiatric Rehabilitation: An Empirical Approach. Guilford Press: New York. 
Davidson L, Shahar G, Stayner DA, Chinman MJ, Rakfeldt J, Tebes JK (2004). Supported socialization for people with psychiatric disabilities: lessons from a randomized controlled trial. Journal of Community Psychology 32, 453-477.

Deegan PE (1988). Recovery: the lived experience of rehabilitation. Psychiatric Rehabilitation Journal 11, 11-19.

Dixon LB, Dickerson FB, Bellack AS, Bennett M, Dickinson D, Goldberg RW, Lehman A, Tenhula WN, Calmes C, Pasillas RM, Peer J, Kreyenbuhl J (2010). The 2009 Schizophrenia PORT psychosocial treatment recommendations and summary statements. Schizophrenia Bulletin 36, 48-70.

Drake RE, Essock SM (2009). The science-to-service gap in real-world schizophrenia treatment: the $95 \%$ problem. Schizophrenia Bulletin 35, 677-678.

Drake RE, Whitley R (2014). Recovery and severe mental illness: description and analysis. Canadian Journal of Psychiatry 59, 236-242.

Drake RE, Goldman HH, Leff HS, Lehman AF, Dixon L, Mueser KT, Torrey WC (2001). Implementing evidencebased practices in routine mental health service settings. Psychiatric Services 52, 179-182.

Drake RE, Skinner J, Goldman HH (2008). What explains the diffusion of treatments for mental illness? American Journal of Psychiatry 165, 1385-1392.

Drake RE, Bond GR, Essock SM (2009). Implementing evidence-based practices for people with schizophrenia. Schizophrenia Bulletin 35, 704-713.

Finnerty MT, Rapp CA, Bond GR, Lynde DW, Ganju VJ, Goldman HH (2009). The state health authority yardstick (SHAY). Community Mental Health Journal 45, 228-236.

Gilmer TP, Stefancic A, Sklar M, Tsemberis S (2013). Development and validation of a housing first fidelity survey. Psychiatric Services 64, 911-914.

Johnson-Kwochka AV, Bond GR, Drake RE, Becker DR, Greene MA (submitted). Prevalence and quality of Individual Placement and Support (IPS) supported employment in the U.S.

Kim SJ, Bond GR, Becker DR, Swanson SJ, Reese SL (2015). Predictive validity of the Individual Placement and Support Fidelity Scale (IPS-25): a replication study. Journal of Vocational Rehabilitation 43, 209-216.

Kreyenbuhl J, Nosse IR, Dixon LB (2009). Disengagement from mental health treatment among individuals with schizophrenia and strategies for facilitating connections to care: a review of the literature. Schizophrenia Bulletin 35, 696-703.

Marshall T, Goldberg RW, Braude L, Dougherty RH, Daniels AS, Ghose SS, George P, Delphin-Rittmon ME (2014). Supported employment: assessing the evidence. Psychiatric Services 65, 16-23.
McGuire AB, Stull LG, Mueser K, Santos M, Mook A, Nicksic C, Rose N, White L, Salyers MP (2012). Development and reliability of an illness management and recovery clinical competence measure. Psychiatric Services 63, 772-778.

McHugo GJ, Drake RE, Whitley R, Bond GR, Campbell K, Rapp CA, Goldman HH, Lutz WJ, Finnerty MT (2007). Fidelity outcomes in the National Implementing EvidenceBased Practices Project. Psychiatric Services 58, 1279-1284.

Monroe-DeVita M, Teague GB, Moser LL (2011). The TMACT: a new tool for measuring fidelity to assertive community treatment. Journal of the American Psychiatric Nurses Association 17, 17-29.

Olfson M, Pincus HA, Pardes H (2013). Investing in evidence-based care for the severely mentally ill. Journal of the American Medical Association 310, 1345-1346.

Rog DJ, Marshall T, Dougherty RH, George P, Daniels AS, Ghose SS, Delphin-Rittmon ME (2014). Permanent supportive housing: assessing the evidence. Psychiatric Services 65, 287-294.

Sackett DL, Rosenberg WM, Gray JA, Haynes RB, Richardson WS (1996). Evidence based medicine: what it is and what it isn't. BMJ 312, 71, doi: http://doi.org/10.1136/ bmj.312.7023.71.

SAMHSA (2015). Case Studies of Three Policy Areas and Early State Innovators: 2014 State Profiles of Mental Health and Substance use Disorder Agencies. HHS Publication No. SMA15-4418. Substance Abuse and Mental Health Services Administration: Rockville, MD.

Seffrin B, Panzano PC, Roth D (2009). What gets noticed: how barrier and facilitator perceptions relate to the adoption and implementation of innovative mental health practices. Community Mental Health Journal 44, 475-484.

Squires D, Anderson C (2015). U.S. health care from a global perspective: spending, use of services, prices, and health in 13 countries. The Commonwealth Fund. http://www.common wealthfund.org/Boston.

Torrey WC, Bond GR, McHugo GJ, Swain K (2012). Evidence-based practice implementation in community mental health settings: the relative importance of key domains of implementation activity. Administration and Policy in Mental Health and Mental Health Services Research 39, 353-364.

Wang PS, Lane M, Olfson M, Pincus HA, Wells KB, Kessler RC (2005). Twelve-month use of mental health services in the United States: results from the National Comorbidity Survey replication. Archives of General Psychiatry 62, 629-640.

Wiltsey Stirman S, Kimberly J, Cook N, Calloway A, Castro F, Charns M (2012). The sustainability of new programs and innovations: a review of the empirical literature and recommendations for future research. Implementation Science 7, 17. doi: 10.1186/1748-5908-7-17. 